\title{
Bulbar conjunctival metastasis from mucoepidermoid carcinoma of parotid-a case report and review of literature
}

\author{
Rajshri Yadav1, Azhar J. Battoo ${ }^{2 *}$, Abdul W. Mir ${ }^{2,3}$ and Altaf G. Haji ${ }^{2}$
}

\begin{abstract}
Background: Mucoepidermoid carcinoma of salivary glands usually metastasizes to the lungs, liver, bone, brain, and skin. We report a rare case of distant metastasis of high-grade mucoepidermoid carcinoma of the parotid to the ipsilateral bulbar conjunctiva of the eye.

Case presentation: Sixty-year-old male of Kashmiri origin presented to our tertiary care referral cancer institute with exophytic lesion of the left bulbar conjunctiva following his treatment for mucoepidermoid cancer of ipsilateral parotid gland, 9 months back. The lesion was biopsied and reported as high-grade mucoepidermoid carcinoma. Radiological imaging showed no other site of recurrence. The patient underwent orbital exenteration and final histopathological evaluation reported the lesion as mucoepidermoid carcinoma.
\end{abstract}

Conclusions: Distal metastasis from mucoepidermoid carcinoma to bulbar conjunctiva is very rare and to the best of our knowledge has not been previously reported.

Keywords: Bulbar conjunctiva, Distal metastasis, Mucoepidermoid carcinoma, Parotid, Case report

\section{Background}

The incidence of distant metastasis seen in mucoepidermoid carcinoma (MEC) of salivary glands is almost $13 \%$ [1]. Distant metastasis is most commonly seen in the lung $(25 \%)$ followed by the liver (25\%) and bone (18\%), respectively [2].

We report here a rare case of isolated distal metastasis of MEC parotid to the bulbar conjunctiva of the ipsilateral eye. The consent for publishing this case report was taken from the institute's ethics committee-Sher-iKashmir Institute of Medical Sciences Ethics Committee. Such a case is unusual and, to our knowledge (following thorough search on PubMed and Google), has not been previously reported.

\section{Case presentation}

A 65-year-old Kashmiri male patient, hypertensive, presented to the Surgical Oncology department of a tertiary care referral center with exophytic lesion of the left

\footnotetext{
* Correspondence: azatmsy@gmail.com

${ }^{2}$ Surgical Oncology, Sher-i-Kashmir Institute of Medical Sciences, Srinagar 190011, India

Full list of author information is available at the end of the article
}

bulbar conjunctiva, following his initial surgery for left parotid gland mucoepidermoid carcinoma. Magnetic resonance imaging of the head and neck along with computed tomographic scan of the chest was done before the previous surgery, which showed lesion confined to the parotid gland, without any regional or distant metastases. The patient underwent radical parotidectomy along with neck dissection followed by radiotherapy. Histopathological examination of the operated specimen had showed features of high-grade MEC (Brandwein's modified AFIP criteria; score 8), and patient was staged as pT4NOM0. After almost 10 months of the surgery, the patient developed visual impairment in the left eye for which he consulted the ophthalmologist, where on examination, lateral bulbar conjunctival growth was seen. The lesion was biopsied and histopathology revealed features of high-grade MEC.

Examination of patient revealed exophytic growth involving mainly lateral aspect of the bulbar conjunctiva. Inferior palpebral fissure was obliterated by the growth; superior palpebral fissure was free. Corneal opacity seen on lateral aspect extended up to the pupil. Both the upper and lower eyelids were thickened (Fig. 1). 


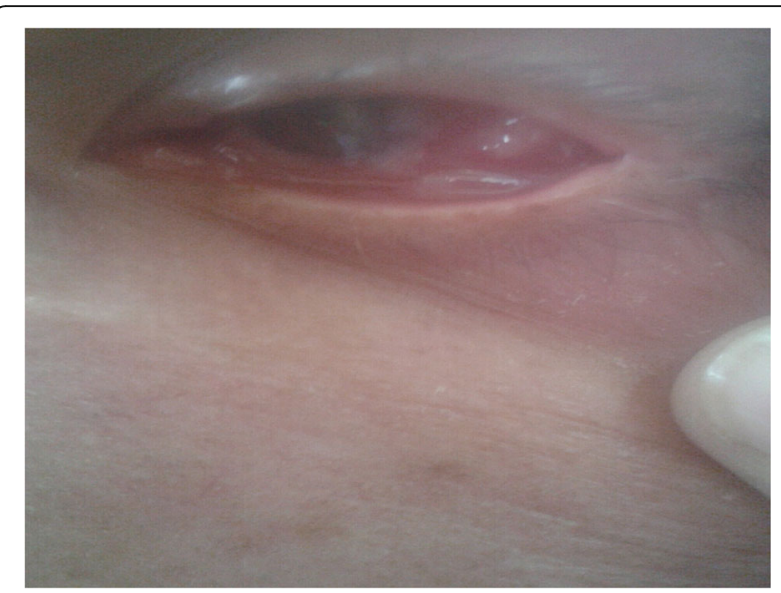

Fig. 1 Preoperative appearance of orbital lesion, showing exophytic growth involving lateral bulbar conjunctiva

Contrast enhanced computed tomography of the brain, neck, and chest revealed evidence of enhancing lesion involving anterolateral wall of the left eyeball and overlying eyelid appeared thickened with no extension into the post-septal compartment (Fig. 2). No evidence of residual or recurrent mass lesion in the left parotid region was seen. No other evidence of loco regional or distant metastasis was seen.

The case was discussed in the Institution's Tumour Board, and patient was planned for left orbital exenteration followed by split thickness skin graft lining for orbital cavity. The patient was explained about the prognosis of the disease, and consent for the procedure was taken. The left orbital exenteration was done along with the excision of the upper and lower eyelids. Split thickness skin graft was harvested from the thigh and grafted at the site of defect.

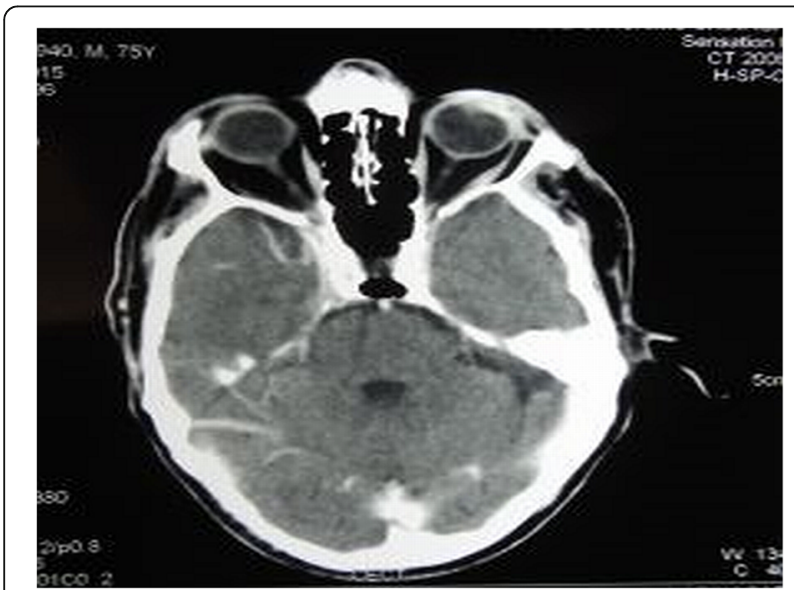

Fig. 2 Preoperative contrast enhanced computed tomography of patient showing enhancing lesion involving anterolateral wall of the left eyeball and thickened overlying eyelid
Histopathological examination of the specimen showed features of mucoepidermoid carcinoma infiltrating up to the sclera, high-grade type (Brandwein's modified AFIP score 7). Infiltration was also seen in the lower eyelid. All resection margins were free of tumor, greater than $5 \mathrm{~mm}$. Optic nerve resection margin was free of tumor (Fig. 3a, b). Post-surgery patient did well with no evidence of loco regional or any other distant recurrence at the time of writing the article.

\section{Discussion}

The aggressiveness of mucoepidermoid carcinomas is graded as per histological grading system introduced by Brandwein et al. [3], which is based on the eight components namely intracystic component $<25 \%(+2)$, aggressive pattern of invasion $(+2)$, anaplasia $(+2)$, perineural invasion $(+3)$, necrosis $(+3),>4$ mitosis/ HPF (highpower field) $(+3)$, bony invasion $(+3)$, and lymphovascular invasion $(+3)$. Scoring for low-grade tumors is 0 , for intermediate grade tumors 2 and 3, and for highgrade tumors $>4$. The microscopic examination of the specimen obtained after orbital exenteration in our patient showed features of extensive necrosis $(+3)$, cystic component $<25 \%(+2)$, and anaplasia $(+2)$, which made a total score of 7, consistent with high-grade MEC. Extravasated mucin was also seen which is an evidence of the aggressive nature of the tumor.

Chen et al. [4] evaluated medical records of 61 patients of parotid gland MEC. A multivariate analysis of the entire patient sample revealed high-grade tumor and $\mathrm{T} 4$ disease as independent predictors of decreased survival in that order (LLR test: $P=0.0001$ and 0.02 , respectively). Out of 61 patients, 20 developed distant metastases, 14 of which were isolated events. Initial sites of distant failure were the following: 16 lungs, 3 bones, and

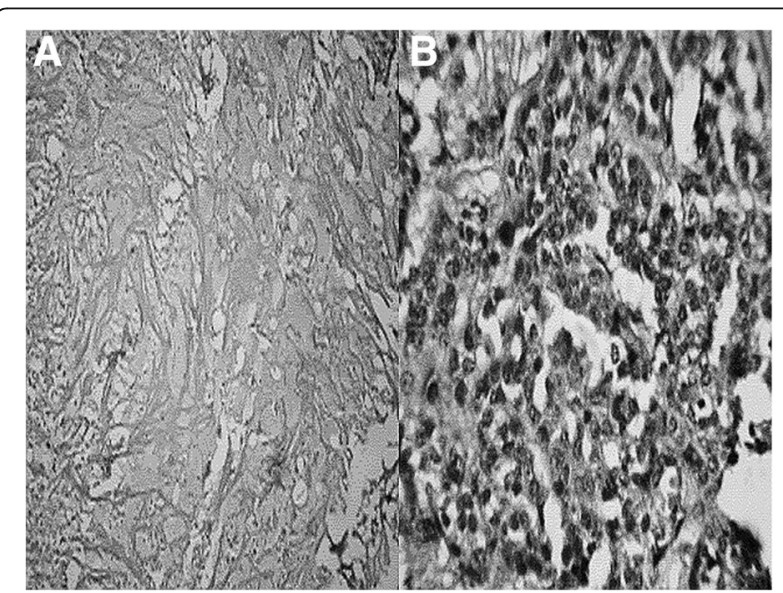

Fig. 3 Hematoxylin and eosin staining (original magnification $\times 40$ ) showing $\mathbf{a}$ areas of extracellular mucin and $\mathbf{b}$ tumor cells showing squamoid differentiation 
1 liver. Median time for development of distant failure was 20 months (range, 6-70). High histologic grade and pathological lymph node metastasis was associated with a sufficiently greater risk of distant metastasis. The 5year distant metastasis-free survival was $87 \%$ for patients, with non-high-grade tumors compared to $47 \%$ for those with high-grade tumors $(P=0.001)$. The 5 -year estimate of distant metastasis-free survival for patients with and without pathological lymph node metastasis was 57 and $80 \%$, respectively $(P=0.03)$. The patient in consideration of the present case report also had T4 disease with invasion into the masseter muscle and highgrade tumor on histopathology.

\section{Conclusions}

To conclude high-grade and T3-T4 MEC, tumors have aggressive behavior and propensity for distant metastasis but metastasis to bulbar conjunctiva is extremely rare and to the best of our knowledge has never been reported.

\section{Abbreviations}

MEC: Mucoepidermoid carcinoma

\section{Acknowledgements}

None.

\section{Funding}

No funding was received by any of the authors.

\section{Availability of data and materials}

The "Availability of data and materials" section concerning the case report is related to all the diagnostic examinations that the patient has been submitted to during his hospitalization. The publication of all these data has been authorized by the Sher-i-Kashmir Institute of Medical Sciences Ethics Committee.

\section{Authors' contributions}

$\mathrm{RS}, \mathrm{AJB}, \mathrm{AWM}$, and $\mathrm{AGH}$ were the treating physicians of the patient. All authors were involved in drafting the manuscript and approved the final manuscript.

\section{Competing interests}

The authors declare that they have no competing interests.

\section{Consent for publication}

Written informed consent was obtained from the patient for the publication of this case report and any accompanying images. A copy of the written consent is available for review by the Editor-in-Chief of this journal.

\section{Ethics approval and consent to participate}

The ethical approval has been received by the Sher-i-Kashmir Institute of Medical Sciences Ethics Committee concerning the publication of this manuscript and any accompanying images. A copy of this document is available for review by the Editor-in-Chief of this journal.

\section{New software}

The authors declare that no new software has been used.

\section{Author details}

'Department of Otorhinolaryngology, Sher-i-Kashmir Institute of Medical Sciences Medical College, Srinagar 190011, India. ${ }^{2}$ Surgical Oncology, Sher-i-Kashmir Institute of Medical Sciences, Srinagar 190011, India. ${ }^{3}$ Department of Surgical Oncology, Sher-i-Kashmir Institute of Medical Sciences, Srinagar 190011, India.
Received: 2 July 2016 Accepted: 22 December 2016

Published online: 07 January 2017

References

1. Mariano FV, da Silva SD, Chulan TC, de Almeida OP, Kowalski LP. Clinicopathological factors are predictors of distant metastasis from major salivary gland carcinomas. Int J Oral Maxillofac Surg. 2011;40:504-9.

2. Walvekar RR, Filho PA, Seenthala RR, et al. Clinicopathological features as stronger prognostic factors than histology or grade in risk stratification of primary parotid malignancies. Head Neck. 2011;33:225-31.

3. Brandwein IK, Wallace DI, Hille JJ, et al. Mucoepidermoid carcinoma: a clinicopathological study of 80 patients. Am J Surg Pathol. 2001;25:835-45.

4. Chen AM, Lau VH, Farwell G, Luu Q Donald PJ. Mucoepidermoid carcinoma of the parotid gland treated by surgery and postoperative radiation therapy: clinicopathological correlates of outcome. Laryngoscope. 2013;123:3049-55.
Submit your next manuscript to BioMed Central and we will help you at every step:

- We accept pre-submission inquiries

- Our selector tool helps you to find the most relevant journal

- We provide round the clock customer support

- Convenient online submission

- Thorough peer review

- Inclusion in PubMed and all major indexing services

- Maximum visibility for your research

Submit your manuscript at www.biomedcentral.com/submit
) Biomed Central 